\title{
FOLLOWING THE PRINCIPLES OF ERGONOMICS AND MUSCULOSKELETAL DISORDERS IN ULTRASONOGRAPHERS
}

\author{
Vanja Jovanovic ${ }^{1}$, Jelena Maric ${ }^{2}$ and Dejan Jovanovic ${ }^{3}$ \\ ${ }^{1}$ Military Medical Academy, Institute of Occupational Medicine, Belgrade, Serbia \\ ${ }^{2}$ Military Medical Academy, Institute of Hygiene, Belgrade, Serbia \\ ${ }^{3}$ Military Medical Academy, Institute of Radiology, Belgrade, Serbia
}

\section{Corresponding author:}

\section{Vanja Jovanovic, MD}

E-mail: jovanovicdrvanja@gmail.com

\section{sciendo}

UDK: 572.087:61-051

331.101 .1

Eabr 2022; 23(4):327-337

DOI: $10.2478 /$ sjecr-2020-0036
Received: 23.03.2020.

Accepted: 21.04.2020.

\begin{abstract}
It has been noticed that doctors who regularly perform ultrasound examinations have different clinical manifestations of musculoskeletal disorders. The aim of this research is to examine the level of knowledge of ultrasonographers regarding preventative measures and health consequences of the forced body positions during work. The total of 75 doctors of both genders, aged 31-50 years, who use ultrasound diagnostics participated in the research. The research was conducted throughout 2016, as a crosssectional study, with the aid of a structured questionaire. The total of $60 \%$ subjects either rarely use the break during working hours or do not have a break at all. The participants most commonly use the movable monitor and the ability to wrap the cable around their arm (73,3\%). This percentage is similar in all age groups. The respondents most often stated that they walk daily $(41,3 \%)$, with no differences among age groups. $25 \%$ of the respondents negate any spine related pains, while over a half said that they experience pain in one segment of the spinal column (cervical, thoracic or lumbar), regardless of the age group. 52\% said that they serch for information on their own accord, while $36 \%$ stated that they are not at all informed. Only in less than $10 \%$ of cases is information provided by the authorities in the institution where the participants are employed, and during regular health examinations, information is given by the designated doctor in 2,7\% of cases. The respondents implement the recommendations regarding safe work and other preventative measures to a very small extent, regardless of gender and age. Most of the respondents experience pain in the spine and joints, which can be related to the work in ultrasound diagnostics. Additionally, doctors are not well-informed regarding the preventative measures.
\end{abstract}

Keywords: Ergonomics, ultrasonography, musculoskeletal disorder. 


\section{INTRODUCTION}

Due to its non-invasiveness, in many areas of medicine, such as cardiology, gynecology or urology, the ultrasound examination is a part of the protocol for diagnosis, as well as for long-term follow-up of a patient's health condition and monitoring of the effects of the therapy.

It has been noticed that a large number of doctors, of various specialties, who regularly perform ultrasound examinations during their practice have different clinical manifestations of musculoskeletal disorders. Work-related musculoskeletal disorders can be defined as injuries which occurred or got worse due to the activities at work. The share of these disorders rises up to $60 \%$ out of all work-related diseases. Various terminology related to these disorders can be found in the literature and some of them are: injury due to repeated straining, cumulative trauma, injury caused by repeated movement (1-3). Among the population of doctors who deal with ultrasound diagnostics, this disorder was first identified in 1993 (4). The prevalence of musculoskeletal symptoms connected to the work of ultrasonographers, in large scale researches, goes up to $80 \%$ (5) and 90\% (6). The typical areas of symptoms reported in previous surveys are the neck and lower back (5-10). These musculoskeletal disorders have different intensities and can manifest as discomfort or intensive pain.

Many following studies showed that ultrasonographers are at a higher risk of numerous musculoskeletal disorders, including wrist disorders (carpal tunnel syndrome, carpal instability, tendinitis), elbow disorders (bursitis, epicondylitis), pain in the shoulders, neck and spine $(11,12)$.

When it comes to the pains in the spinal column, considering the risk factors, some are connected to the work environment and work process, while some are not. Individual risk factors include the previous injury history and spinal column diseases, anthropometric characteristics, gender and age. The highest risk period for men is around the age of 40 , and for women between the age of 50 and 60 .

Studies have also shown that the relative risk of the occurrence of pain in the lumbar area of the spine is greater in men taller that $180 \mathrm{~cm}$ and women taller than $170 \mathrm{~cm}$, compared to $10 \mathrm{~cm}$ shorter persons. People with higher body mass index, of both genders, are also at a higher risk, as well as those with decreased lumbar lordosis. Nowadays, it is believed that individual risk factors define the basis of the likelihood for the occurrence and the development of musculoskeletal disorders, but that the illness will develop depending on the other factors, most important of which is work environment, i.e. irregular position of the body during work (13). Also, overworking, prolonged straining of certain muscle groups, work operations which require strong muscle contractions, long forced body positions, repeated movements and prolonged static load - the transducer is held pressed onto the surface of a patient's body, are also relevant (13).
The symptoms of work related musculoskeletal disorders can be intermittent or temporary, they can last during the entire work day or they can occur at night. If the first symptoms are disregarded, they can lead to serious, chronic, incapacitating symptoms and disorders such as the loss of sensibility or muscle weakness (13).

In cases of the work related disorders in ultrasonographers, the most common diagnosis is tendon and/or tendon sheath inflammation, i.e. tendinitis or tenosynovitis. The most common cause of tendinitis is repeated straining, i.e. performing the same type of examination without sufficient time for rest between two examinations. Ultrasonographers specialized only for one type of examination, such as gynecologists or cardiologists, are at a particular risk. The conclusion of a doctoral dissertation published in Sweden in 2018, which included almost all female doctors which perform heart ultrasonography, is the recommendation that visual ergonomics and optimal adaptability of the equipment should be improved, i.e. that the equipment is designed in a way which allows for variations of work positions, since none of the applied techniques was optimal (14).

In order for the muscles to relax, sufficient recovery time should be allocated after prolonged work in a forced body position. A short recess is recommended after every three examinations, during which it is advised to stand up, walk around the room and stretch. Such preventative measures should become a habit, which will ensure health protection despite occupational risk.

The aim of this research is to examine the level of knowledge of ultrasonographers regarding preventative measures and the level of application of these measures, as well as health consequences of the forced body positions during work.

\section{METHODS}

In total, 75 respondents of both genders and different age groups who practice ultrasound diagnostics took part in the research. They were divided into three groups in a ten-year range from 31 to over 50 years of age. The research was conducted in of seven institutions in total - primary, secondary and tertiary health care institutions, in Belgrade and Obrenovac. All the participants submitted a written informed consent for the participation in the research.

The data was collected through a structured questionnaire which had been adapted according to the questionnaires used in similar researches $(15,16,17)$. The questionnaire was firstly validated and it consisted of five groups of questions referring to: demographic data, workload, preventative measures implementation during work, health consequences and awareness of the topics relevant to this research. With the aim of quantification, the obained data regarding the implementation of preventative measures during work, health 
consequences and awareness was translated from categories to numerical values by evaluating the responses according to the key.

The data was presented using the methods of descriptive statistics: arithmetic mean, standard deviation and proportion frequency. Normality of distribution was examined using the Kolmogorov-Smirnov test. The significance of the differences among the groups was examined using the KruskalWallis test, i.e. the $\chi^{2}$ test for the qualities in terms of categories.

\section{RESULTS}

\section{Demographic data}

At the moment of the research, the average number of years of service of the respondents was 19, and on average, they had 11 years of experience in ultrasound diagnostics. On average, they perform ultrasound examinations 3.5 days a week, 4.7 hours a day and they see 16 patients a day.

The total of 75 respondents participated in the study, 39 $(52 \%)$ of which were men and $36(48 \%)$ were women. All three age groups consisted of a similar number of respondents $(p>0.05)$, with similar gender distribution $(p>0.05)$.

The majority of the respondents, 52 of them $(69.3 \%)$, were radiologists, men and women equally. However, out of seven internists and six general physicians, the majority were women, while the specialists in different surgical branches (urology, general surgery and otorhinolaryngology) were all men and there were seven of them.

Image 1. The number of respondents of both genders in different specialties

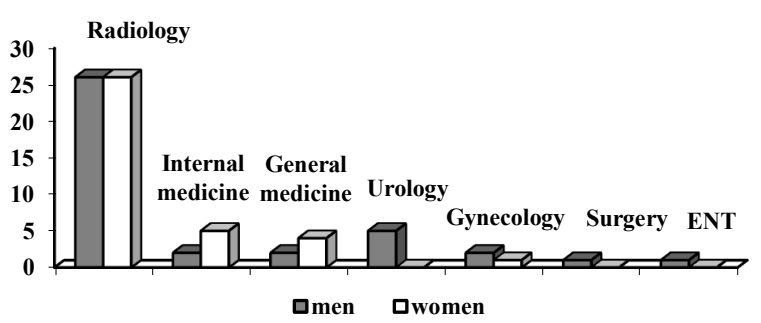

\section{Workload}

On average, the respondents had 19,30 $\pm 9,14$ years of service (from $9.43 \pm 3.37$ years in the youngest to $28.80 \pm 4,51$ in the oldest age group). The number of years of work in the field of ultrasound diagnostics follows the total number of years of service and increases with the age (from $4.05 \pm 2.22$ to $17.70 \pm 6.13$ ). However, the number of days per week when the respondents are engaged in ultrasound examinations, as well as the number of hours per day during which they
Finally, for post hoc analysis, Mann-Whitney test was used. The relation among the examined qualities was tested using Spearman's rank correlation coefficient $(\rho)$. The results were processed in the statistical programmes Excel for Windows and Origin. Statistical significance was accepted at $p<0.05$.

The research was designed as a cross-sectional study and was conducted during 2016.

perform the examinations, do not differ among age groups $(p>0.05)$. When the engagement in the ultrasound diagnostics is expressed on a weekly basis, a slightly lower number of examinations per week can be noticed, as well as a lower number of hours per week, in the group of the participants of over 50 years of age compared to the two younger groups, though without statistical significance $(p>0.05)$. These results are presented in Table 1.

\section{The implementation of preventative measures during work}

Out of all the respondents, the total of $60 \%$ either rarely have a break during working hours or do not have a break at all, and the percentage is similar in all age groups $(p>0.05)$. A very small number of participants have a break after each examination $(6.7 \%)$, the smallest number of these doctors is in the group above the age of 50 (only $3.6 \%$ ), which is statistically significantly less compared to both younger age groups $(p<0.05)$. In respect to this parameter, men and women do not differ, regardless of the age group $(p>0.05)$. The results are shown in Table 2. 
Table 1. Workload characteristics of the respondents in different age groups

\begin{tabular}{lccccccc}
\hline Yrs & $\begin{array}{c}\text { Years of } \\
\text { service }\end{array}$ & $\begin{array}{c}\text { Ultra- } \\
\text { sound } \\
\text { (years of } \\
\text { service) }\end{array}$ & $\begin{array}{c}\text { Ultra- } \\
\text { sound } \\
\text { (days per } \\
\text { week) }\end{array}$ & $\begin{array}{c}\text { Ultra- } \\
\text { sound } \\
\text { (hours } \\
\text { per day) }\end{array}$ & $\begin{array}{c}\text { No. of } \\
\text { patients } \\
\text { per day }\end{array}$ & $\begin{array}{c}\text { Ultra- } \\
\text { sound } \\
\text { (hours per } \\
\text { week) }\end{array}$ & $\begin{array}{c}\text { Ultra- } \\
\text { sound } \\
\text { (patients } \\
\text { per week) }\end{array}$ \\
\hline \multirow{2}{*}{$\mathbf{3 1 - 4 0}$} & 9.43 & 4.05 & 3.48 & 5.10 & 18.33 & 17.67 & 67.14 \\
& \pm 3.37 & \pm 2.22 & \pm 1.57 & \pm 1.81 & \pm 9.18 & 9.97 & \pm 52.03 \\
\hline \multirow{2}{*}{$\mathbf{4 1 - 5 0}$} & 17.00 & 10.80 & 3.90 & 4.60 & 16.90 & 17.60 & 66.10 \\
& \pm 5.20 & \pm 5.80 & \pm 1.50 & \pm 2.30 & \pm 11.10 & \pm 11.70 & \pm 57.00 \\
\hline \multirow{2}{*}{ Over 50 } & 28.80 & 17.70 & 3.32 & 4.43 & 14.54 & 12.43 & 47.32 \\
& \pm 4.51 & \pm 6.13 & \pm 1.79 & \pm 2.07 & \pm 5.01 & \pm 7.38 & \pm 30.11 \\
\hline \multirow{2}{*}{ Total } & 19.30 & 11.00 & 3.57 & 4.69 & 16.41 & 15.67 & 59.38 \\
& \pm 9.14 & \pm 7.50 & \pm 1.65 & \pm 2.09 & \pm 8.71 & \pm 9.97 & \pm 47.42
\end{tabular}

Table 2. The use of a break during working hours, in respect to gender and age groups

\begin{tabular}{llccc}
\hline Yrs & Break & Total & Men & Women \\
\hline \multirow{4}{*}{$31-40$} & Rarely/never has a break & $12(57.1 \%)$ & $8(61.5 \%)$ & $4(50 \%)$ \\
& As they choose & $5(23.9 \%)$ & $4(30.8 \%)$ & $1(12.5 \%)$ \\
& Predetermined & $2(9.5 \%)$ & $0(0 \%)$ & $2(25 \%)$ \\
& After each examination & $2(9.5 \%)$ & $1(7.7 \%)$ & $1(12.5 \%)$ \\
\hline \multirow{4}{*}{$\mathbf{4 1 - 5 0}$} & Rarely/never has a break & $17(65.4 \%)$ & $10(76.9 \%)$ & $7(53.8 \%)$ \\
& As they choose & $4(15.4 \%)$ & $1(7.7 \%)$ & $3(23.1 \%)$ \\
& Predetermined & $3(11.5 \%)$ & $2(15.4 \%)$ & $1(7.7 \%)$ \\
& After each examination & $2(7.7 \%)$ & $0(0 \%)$ & $2(15.4 \%)$ \\
\hline \multirow{5}{*}{ Over 50 } & Rarely/never has a break & $16(57.1 \%)$ & $6(46.1 \%)$ & $10(66.7 \%)$ \\
& As they choose & $3(10.7 \%)$ & $2(15.4 \%)$ & $1(6.7 \%)$ \\
& Predetermined & $8(28.6 \%)$ & $4(30.8 \%)$ & $4(26.6 \%)$ \\
& After each examination & $\mathbf{1}(\mathbf{3 . 6 \%} \%$ & $1(7.7 \%)$ & $0(0 \%)$ \\
\hline \multirow{5}{*}{ Total } & Rarely/never has a break & $45(60.0 \%)$ & $24(61.6 \%)$ & $21(58.3 \%)$ \\
& As they choose & $12(16.0 \%)$ & $7(17.9 \%)$ & $5(13.9 \%)$ \\
& Predetermined & $13(17.3 \%)$ & $6(15.4 \%)$ & $7(19.5 \%)$ \\
\hline \multirow{2}{*}{ the group } & After each examination & $5(6.7 \%)$ & $2(5.1 \%)$ & $3(8.3 \%)$ \\
& of respondents over 50 years of age compared to both younger groups $p<0.05 ;$
\end{tabular}

In accordance with the previously stated, not only do respondents rarely have a break during working hours, but also the break between examinations. If they do use it, it is usually no longer than five minutes. Age groups do not differ in this respect, nor do men and women within an age group, except in case of the group of respondents over 50 years of age, where all 15 women $(100 \%)$ reported that they do not have a break at all between two examinations, which is statistically significantly different from the women in other age groups, as well as from the men in the same age group $(p<0.05)$ (Table 3).

Table 3. The duration of a break between examinations in respect to gender in different age groups

\begin{tabular}{clccc}
\hline \multirow{2}{*}{ Yrs } & \multicolumn{1}{c}{ Duration of a break } & Total & Men & Women \\
\hline \multirow{2}{*}{$\mathbf{3} 1-40$} & Non-existent & $14(66.7 \%)$ & $9(69.2 \%)$ & $5(625 \%)$ \\
& Up to 5 minutes & $6(28.6 \%)$ & $4(30.8 \%)$ & $2(25.0 \%)$ \\
& Over 5 minutes & $1(4.7 \%)$ & $0(0 \%)$ & $1(12.5 \%)$ \\
\hline
\end{tabular}




\begin{tabular}{clccc}
\hline \multirow{2}{*}{ Yrs } & \multicolumn{1}{c}{ Duration of a break } & Total & Men & Women \\
\hline \multirow{2}{*}{$\mathbf{4 1 - 5 0}$} & Non-existent & $17(65.4 \%)$ & $10(76.9 \%)$ & $7(53.8 \%)$ \\
& Up to 5 minutes & $8(30.8 \%)$ & $3(23.1 \%)$ & $5(38.5 \%)$ \\
& Over 5 minutes & $1(3.8 \%)$ & $0(0 \%)$ & $1(7.7 \%)$ \\
\hline \multirow{2}{*}{ Over 50 5} & Non-existent & $24(85.7 \%)$ & $9(69.2 \%)$ & $\mathbf{1 5 ( 1 0 0 . 0 \% ) ^ { * }}$ \\
& Up to 5 minutes & $4(14.3 \%)$ & $4(30.8 \%)$ & $0(0 \%)$ \\
& Over 5 minutes & $0(0 \%)$ & $0(0 \%)$ & $0(0 \%)$ \\
\hline \multirow{3}{*}{ Total } & Non-existent & $55(73.3 \%)$ & $28(71.8 \%)$ & $27(75.0 \%)$ \\
& Up to 5 minutes & $18(24.0 \%)$ & $11(28.2 \%)$ & $7(19.4 \%)$ \\
& Over 5 minutes & $2(2.7)$ & $0(0 \%)$ & $2(5.6 \%)$ \\
\hline
\end{tabular}

$* p<0.05$; women over 50 compared to women in younger groups;

$* p<0.05$; women over 50 compared to men over 50 .

As a convenience during work, the respondents mostly use the movable monitor and the possibility to wrap the cable around their arm. This combination is used by $73.3 \%$ of all the respondents, and this percentage is similar in all age groups $(p>0.05)$. Five respondents $(6.7 \%)$, besides these two conveniences, also use a cuff, while only one respondent claimed that they did not use any of the conveniences, not even the movable monitor (Table 4). None of the respondents in the entire study stated that they used a cushion or a rolledup towel as a support for the arm with which they hold the transducer.

Table 4. The use of conveniences during work in different age groups

\begin{tabular}{clc}
\hline Yrs & \multicolumn{1}{c}{ Use of conveniences } & Frequency \\
\hline \multirow{3}{*}{$\mathbf{3 1 - 4 0}$} & None & $1(4.8 \%)$ \\
& Only the movable monitor & $3(14.2 \%)$ \\
& The movable monitor and wrapped cable & $16(76.2 \%)$ \\
& The movable monitor, wrapped cable and a cuff & $1(4.8 \%)$ \\
\hline \multirow{3}{*}{$\mathbf{4 1 - 5 0}$} & None & $0(0 \%)$ \\
& Only the movable monitor & $8(30.8 \%)$ \\
& The movable monitor and wrapped cable & $17(63.4 \%)$ \\
& The movable monitor, wrapped cable and a cuff & $1(3.8 \%)$ \\
\hline \multirow{3}{*}{ Over 50 } & None & $0(0 \%)$ \\
& Only the movable monitor & $3(10.7 \%)$ \\
& The movable monitor and wrapped cable & $22(78.6 \%)$ \\
& The movable monitor, wrapped cable and a cuff & $3(10.7 \%)$ \\
\hline \multirow{3}{*}{ Total } & None & $1(1.33 \%)$ \\
& Only the movable monitor & $14(18.7 \%)$ \\
& The movable monitor and wrapped cable & $55(73.3 \%)$ \\
& The movable monitor, wrapped cable and a cuff & $5(6.7 \%)$ \\
\hline
\end{tabular}

When describing their physical activity, the participants mostly stated that they go for a walk every day ( $41.3 \%$ of all the respondents), and there is no difference among age groups $(p>0.05)$. A similar percentage said that they were not at all physically active, except in in the 41-50 age group, where the percentage of the physically inactive is $26.9 \%$. This is statistically significantly less compared to the other two groups $(42.8 \%$ in the group of the respondents younger than 40 , and $46.4 \%$ in the group of the respondents older than $50), p<0.05$. Fewer than $25 \%$ of the respondents do an organized physical activity, and this percentage decreases with age, but with no statistical significance. Only one participant practiced yoga, as a way of stretching and relaxation of the locomotor system. The results are presented in Table 5 .

Table 5. The type and amount of physical activity in different age groups

\begin{tabular}{llcc}
\hline Yrs & \multicolumn{1}{c}{ Physical activity } & Presence & $\begin{array}{c}\text { Duration } \\
\text { (hours/week) }\end{array}$ \\
\hline \multirow{2}{*}{$31-40$} & Not physically active & $9(42.8 \%)$ & \\
& Organized sports activity & $5(23.8 \%)$ & $2.4 \pm 2.3$ \\
& Yoga, Pilates & $1(4.8 \%)$ & \\
& Walk & $6(26.6 \%)$ & \\
\hline
\end{tabular}




\begin{tabular}{|c|c|c|c|}
\hline Yrs & Physical activity & Presence & $\begin{array}{c}\text { Duration } \\
\text { (hours/week) }\end{array}$ \\
\hline \multirow{4}{*}{$41-50$} & Not physically active & $7(26.9 \%) *$ & \multirow{4}{*}{$2.6 \pm 1.7$} \\
\hline & Organized sports activity & $5(19.2 \%)$ & \\
\hline & Yoga, Pilates & $0(0 \%)$ & \\
\hline & Walk & $14(53.9 \%)$ & \\
\hline \multirow{4}{*}{ Over 50} & Not physically active & $13(46.4 \%)$ & \multirow{4}{*}{$2.0 \pm 1.9$} \\
\hline & Organized sports activity & $4(14.3 \%)$ & \\
\hline & Yoga, Pilates & $0(0 \%)$ & \\
\hline & Walk & $11(39.3 \%)$ & \\
\hline \multirow{4}{*}{ Total } & Not physically active & $29(38.7 \%)$ & \multirow{4}{*}{$2.3 \pm 1.6$} \\
\hline & Organized sports activity & $14(18.7 \%)$ & \\
\hline & Yoga, Pilates & $1(1.3 \%)$ & \\
\hline & Walk & $31(41.3 \%)$ & \\
\hline
\end{tabular}

\section{Health issues analysis}

About a quarter of the respondents negated any spinal column related pain, while over a half stated that they have pains in one segment of the spinal column (cervical, thoracic or lumbar). This percentage is similar in all age groups ( $p>0.05)$. Similar distribution can be noticed when the frequency of pain in arm joints is examined (shoulder, elbow and wrist), but there is statistically significantly higher percentage of persons with pain in two joints in 41-50 age group compared to the other two age groups $(p<0.05)$. The results are presented in Tables 6 and 7 .

Table 6. The presence of spine related pain in different age groups

\begin{tabular}{clc}
\hline Yrs & \multicolumn{1}{c}{$\begin{array}{c}\text { Pain in the spine } \\
\text { (cervical, thoracic, lumbar) }\end{array}$} & Frequency \\
\hline \multirow{4}{*}{$\mathbf{3 1 - 4 0}$} & Does not experience pain in the spine & $5(23.8 \%)$ \\
& Experiences pain in one segment & $13(61.9 \%)$ \\
& Experiences pain in two segments & $1(4.8 \%)$ \\
& Experiences pain in all three segments & $2(9.5 \%)$ \\
\hline \multirow{4}{*}{$\mathbf{4 1 - 5 0}$} & Does not experience pain in the spine & $6(23.1 \%)$ \\
& Experiences pain in one segment & $16(61.5 \%)$ \\
& Experiences pain in two segments & $4(15.4 \%)$ \\
& Experiences pain in all three segments & $0(0 \%)$ \\
\hline \multirow{3}{*}{ Over 50 } & Does not experience pain in the spine & $8(28.6 \%)$ \\
& Experiences pain in one segment & $14(50.0 \%)$ \\
& Experiences pain in two segments & $5(17.8 \%)$ \\
& Experiences pain in all three segments & $1(3.6 \%)$ \\
\hline \multirow{3}{*}{ Total } & Does not experience pain in the spine & $19(25.3 \%)$ \\
& Experiences pain in one segment & $43(57.3 \%)$ \\
& Experiences pain in two segments & $10(35.7 \%)$ \\
& Experiences pain in all three segments & $3(10.7 \%)$ \\
\hline
\end{tabular}

Table 7. The presence of pain in joints in different age groups

\begin{tabular}{clc}
\hline Yrs & \multicolumn{1}{c}{ Pain in joints (wrist, elbow, shoulder) } & Frequency \\
\hline \multirow{3}{*}{$\mathbf{3 1 - 4 0}$} & Does not experience pain in the joints & $5(23.8 \%)$ \\
& Experiences pain in one joint & $16(76.2 \%)$ \\
& Experiences pain in two joints & $0(0 \%)$ \\
& Experiences pain in all three joints & $0(4.8 \%)$ \\
\hline \multirow{3}{*}{$\mathbf{4 1 - 5 0}$} & Does not experience pain in the joints & $7(26.9 \%)$ \\
& Experiences pain in one joint & $12(46.1 \%)$ \\
& Experiences pain in two joints & $\mathbf{6 ( 2 0 . 1 \% ) ^ { * }}$ \\
& Experiences pain in all three joints & $1(3.9 \%)$ \\
\hline \multirow{2}{*}{ Over 50 } & Does not experience pain in the joints & $5(17.9 \%)$ \\
\hline
\end{tabular}




\begin{tabular}{clc}
\hline Yrs & \multicolumn{1}{c}{ Pain in joints (wrist, elbow, shoulder) } & Frequency \\
\hline \multirow{6}{*}{ Total } & Experiences pain in one joint & $20(71.4 \%)$ \\
& Experiences pain in two joints & $3(10.7 \%)$ \\
& Experiences pain in all three joints & $0(0 \%)$ \\
\hline & Does not experience pain in the joints & $17(22.7 \%)$ \\
& Experiences pain in one joint & $48(64.0 \%)$ \\
& Experiences pain in two joints & $9(12.0 \%)$ \\
& Experiences pain in all three joints & $1(1.3 \%)$ \\
\hline
\end{tabular}

When health issues are ranked, relatively low scores are obtained in all three age groups (5.64 to 5.71 points out of the maximum 30). Age groups did not show statistically significant differences $(p>0.05)$. Although there is a trend of higher scores in the female subgroup compared to men in all age groups, the differences are not statistically significant. (Table 8).

Table 8. Average score values of health issues in different age groups

\begin{tabular}{cccc}
\hline Yrs & Total & Men & Women \\
\hline $\mathbf{3 1 - 4 0}$ & $5.71 \pm 4.30$ & $5.23 \pm 3.61$ & $6.5 \pm 5.42$ \\
$\mathbf{4 1 - 5 0}$ & $5.69 \pm 3.99$ & $4.92 \pm 3.88$ & $5.66 \pm 3.85$ \\
Over 50 & $5.64 \pm 3.36$ & $4.77 \pm 3.11$ & $6.40 \pm 3.48$ \\
\hline Total & $5.68 \pm 3.78$ & $4.90 \pm 3.45$ & $6.44 \pm 4.06$ \\
\hline
\end{tabular}

Even though health issue scores are low, there is still statistically significant correlation between that parameter and workload of the respondents, observed through the number of patients examined weekly, in the 41-50 age group. In this group, health issue score also significantly correlates with the number of hours per week during which the respondents are engaged in ultrasound diagnostics (Images 2 and 3). Health issue score also significantly correlates with the number of performed ultrasound examinations per day, not only in this, but in the younger age group as well (Image 4).

Image 2. Correlation between the number of patients per week and the health issue score in different age groups

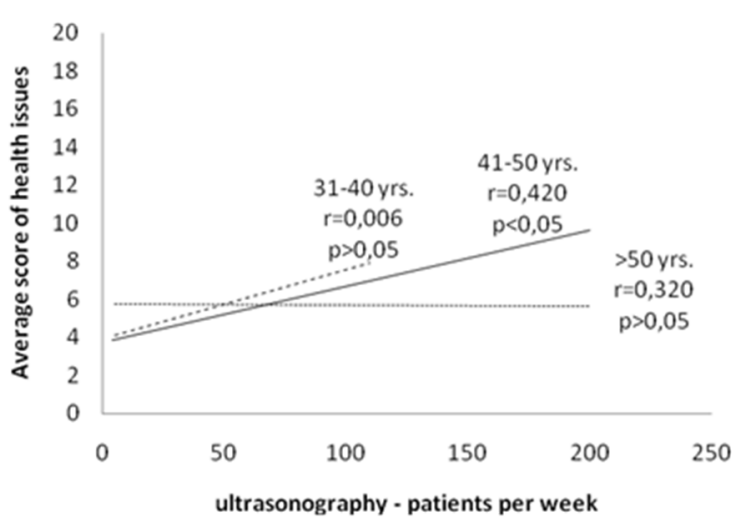

Image 3. Correlation between the number of hours at ultrasound diagnostic jobs per day and the health issues score in different age groups

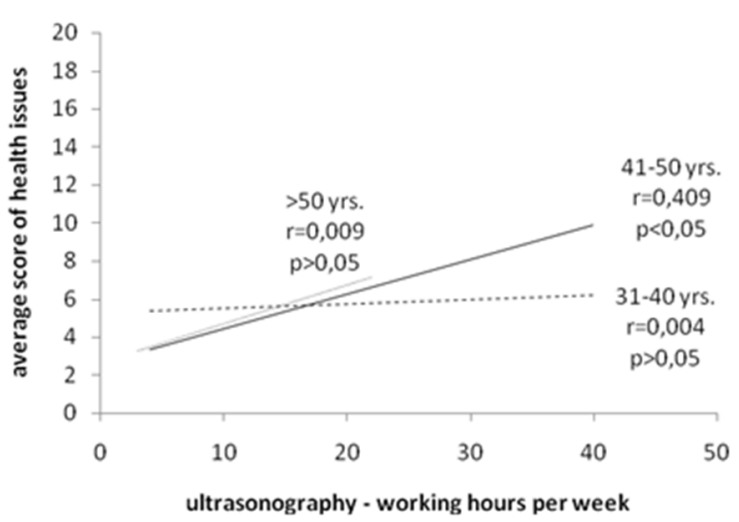

Image 4. Correlation between the number of examinations per week and the health issues score in different age groups

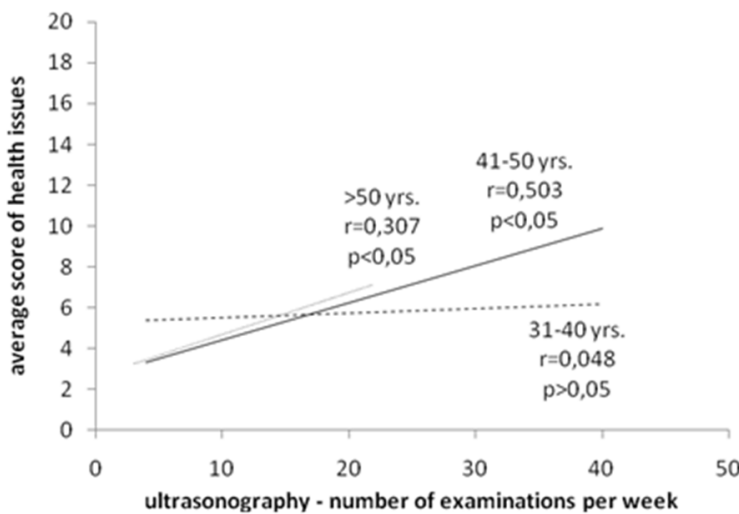

With the aim to determine whether the application of preventative measures influences the mitigation of health issues, 
we examined the correlation between the preventative measures implementation score and the health issues score. The obtained correlation coefficients did not point to statistically significant correlation of these two indicators in any of the age groups.

\section{Awareness of the respondents}

The part of the questionnaire which refers to the employees' awareness of their body position during work and the application of other preventative measures gave the following results:

When it comes to the way in which the respondents get informed about these topics, over a half $(52 \%)$ stated that information search was self-initiated, while $36 \%$ said they were not at all informed. Only in less than $10 \%$ of cases was the information provided by the authorities in the institution in which they are employed, and during regular health examinations, information was given by the designated doctors in $2,7 \%$ of cases. To the question who is responsible for providing the information regarding these topics in the institutions in which they are employed, almost half of the participants (48\%) responded that they think that it is none of the employees, while additional $28 \%$ do not know who is responsible. $10,7 \%$ of the respondents knows that occupational health service is responsible, $9,3 \%$ said that it is persons responsible for health and safety at work, and $4 \%$ said that it is the direct management. $40 \%$ of the respondents said that the communication with regard to such topics in their institutions is informal, while $26,7 \%$ thinks that there is no any communication. Only $20 \%$ of the respondents communicate about these topics in meetings, expert seminars and within continuous medical education, while the remaining $13,3 \%$ use the Internet as the only communication tool. Half of the respondents think that not enough attention is given to these topics in the institutions where they work, nor are they satisfied with the amount and usability of the obtained information. However, the number of respondents who assessed their knowledge on this topic as sufficient is significantly higher than expected - it is $38,7 \%$. $37,3 \%$ of the respondents are partially satisfied with their knowledge, while $24 \%$ are not satisfied.

The fact that the awareness of these topics is very low is supported by the average awareness scores. Out of the maximum 34 points, average scores are $12,00 \pm 6,87$ in the $31-40$ age group, $12,15 \pm 8,23$ in the 41-50 age group and in the over 50 age group the score is the lowest $(8,21 \pm 6,58)$, which is statistically significantly less compared to both younger groups $(p<0.05)$ (Table 9).

The majority of the respondents $(72 \%)$ believe that it would be best if the information regarding this issue were presented through training and practical work and through printed materials $(61.3 \%)$. They think that they would benefit from mandatory meetings and seminars to a lesser extent $(46.7 \%)$, and the least from consulting the Internet sites (22.7\%).
Table 9. Average score values for the awareness in different age groups

\begin{tabular}{|c|c|c|}
\hline Yrs & Total & $\begin{array}{c}\text { Significance of the } \\
\text { difference }\end{array}$ \\
\hline $31-40$ & $12.00 \pm 6.87$ & $n . s$. \\
\hline $41-50$ & $12.15 \pm 8.23$ & n.s. \\
\hline Over 50 & $8.21 \pm 6.58$ & $\begin{array}{l}\quad \boldsymbol{p}<\mathbf{0 . 0 5} \text { compared } \\
\text { to the younger groups }\end{array}$ \\
\hline Total & $10.64 \pm 7.42$ & $p<0.05$ \\
\hline
\end{tabular}

\section{Discussion}

In modern world, there is an increasing need for highly specialized experts in various fields of work. Ultrasound diagnostics is one such field which is more and more present in medical practice. Beside the increased need for experts of such profile, there is also the need for the upgrade of the work environment in terms of the improvement of the ergonomic characteristics of the work place.

Some of the conducted studies showed that more than $80 \%$ of ultrasonographers in all specialties, occasionally or constantly feel pain while performing ultrasound examinations, which, on average, as a consequence resulted in 23 hours (2.96 days) of inability to do ultrasound examinations annually (4.18). Average time from the start of regular ultrasound examinations of patients to the occurrence of first musculoskeletal disorders is around five years (19). In order to better understand musculoskeletal disorders in ultrasonographers, various studies examined possible causes of the disorders, such as the number of ultrasound examinations per day and per week, the duration of a break between two examinations, etc. On the other hand, more and more attention is paid to the development of the preventative measures and procedures, which are introduced into the work process through the rules of good practice, and with the aim to limit the occurrence of detrimental positions so as to prevent the development of musculoskeletal disorders (20).

Since 1920s, numerous researches have been conducted which have established the incidence of the diseases of $84 \%$ among this population, although there are researches which show much higher incidence, rising up to $90 \%$ (21). Such increase if the incidence can be explained in several ways. Firstly, there has been an increase in the life expectancy of ultrasonographers. When the era of ultrasound diagnostics began 50 years ago, only $8.3 \%$ of ultrasonographers were older than 50. By 2008, this percentage had grown to $30 \%$. Furthermore, workload has also increased. In the first research of this kind, conducted in 1992, on average, doctors performed about 1500 diagnostic procedures of this type a year, whereas in 2008 , it was 2700 procedures, which was an increase of $55.7 \%$ (1). In our study, the percentage of doctors over the age of 50 who practice ultrasonography was $37.3 \%$ and they have a bit lower workload, i.e. they see 14.54 patients a day, compared to the two younger age groups. The number of examinations on a daily level has also increased 
to approximately 10 , which is the consequence of the widened range of indications for ultrasound examinations and the advancement of the method which is being increasingly used. The increase in the incidence of the musculoskeletal disorders among the population of ultrasonographers can also be partially explained by drawing attention to this problem. Namely, these diseases have become more and more associated with workplace risks, which was not the case initially: doctors suffered from pains outside workplace as well, sometimes at night, which can indicate that the problem is connected to other factors, rather than professional exposure. Workload of a person who performs ultrasound examinations is higher due to the increase in workload in general. This fact points to the reduction of time allocated for the muscle recovery from the forced position. Research has shown that a muscle can work all day without fatigue if the contraction force does not exceed $10 \%$ of the maximum, since blood flow through the muscle in this case enables unhindered elimination of the acidic metabolic products, with simultaneously good supply of oxygen and energy. However, when the frequency and the duration of the load exceed the capabilities of muscles and tendons to adapt, inflammation occurs, which is then followed by degeneration, microtraumas, and finally, scarring (22).

In our research, men and women were equally present, both in the total number of the respondents and in each age group. In the majority of the available literature, researches predominantly involved women $(2,3,21,23)$, which makes our results somewhat more interesting.

In the segment of the questionnaire dealing with workload, the obtained results point to the fact that the respondents over the age of 50 are a bit less burdened, observed through the number of examinations per week, as well as the number of hours performing these jobs per week. In one of the first studies which examined the prevalence of these problems among the population of ultrasonographers and the correlation of their physical symptoms with workload and work habits, a questionnaire was also used (2). The total of 149 questionnaires were analyzed, mostly $(80 \%)$ filled in by women. The author proved a positive correlation between the severity of the health issues on one hand, and the number of years of service in ultrasound diagnostic jobs, the number of hours and the number of examinations per week on the other. Our results are in accordance with this study, since we also confirmed a direct correlation between the number of examinations per week and the severity of health issues, though only in the 41-50 age group. Nevertheless, in all age groups, except the youngest one, we proved a statistically significant correlation between the number of examinations per day and the severity of health issues. The same authors state that, in their study, they identified $66 \%$ of ultrasonographers with health issues connected with work habits (2). In our study, the percentage of the respondents with health issues is somewhat bigger, around $70 \%$ in all age groups, regardless of whether the issues are related to the spine or joints. Other studies, however, report an even larger percentage of persons with health issues related to musculoskeletal system and it is between $80 \%$ and $90 \%(5,6,7,12,24,25)$. A survey study which examined pain in the spinal column in doctors who practice ultrasonography, aged around 28 , showed that $84 \%$ of the respondents suffered from pain. Our results in the 3140 age group are quite similar, showing that approximately $23 \%$ do not suffer from pain in the spinal column (25). A research conducted with the sample of 26 female sonographers, who had filled in a standardized questionnaire, also showed a significant influence of workload on the frequency of musculoskeletal symptoms. They were present in $96 \%$ of cases, despite the respondents' young age (37 years of age on average) and lower number of years of service, both total $(9.2$ years) and on ultrasonography jobs (6,4 years), compared to our respondents (3).

The data in the literature shows that the risk of these disorders rapidly increases after five years of work in ultrasound diagnostics (26), and our respondents have far more years of service in these jobs (11 years on average, for the whole group). By further analyzing workload, it is seen that the number of ultrasound examinations per week is 60 , which is lower than the bottom limit (100 examinations per week) for the development of health issues (26).

Ultrasonographers have various preventative measures at their disposal, some of them are technical-technological, requiring additional equipment, while others refer to programmed physical activity and better work organization $(27,28,29,30)$. It has been shown that doctors spend $68 \%$ of examination time in a position which implies shoulder abduction greater than $30^{\circ}, 63 \%$ of time with the external shoulder rotation greater that $30^{\circ}$, and $37 \%$ of time with their neck leaning forward, to the side or twisted at the angle greater than $20^{\circ}$. Other than that, with the aid of electromyographic testing of the shoulder muscles, the authors have confirmed a higher risk due to the neck and shoulder muscles straining. In a study from 2016, the authors concluded that ultrasonographers consider their work stimulating but also physically exhausting. They are aware of the ergonomic positions during work, though the comfort of the patient and obtaining good ultrasonographic images often took precedence over the work position (31).

Physical activity is of the utmost importance for the preservation of the overall well-being, especially for the health of the locomotor system. Our respondents do not have a habit of keeping fit by doing an organized physical activity, at least three times a week in the duration of one hour - running, playing football, basketball, tennis, swimming, or doing any other predominantly aerobic sport. Instead, they stated that they go walking $(41.3 \%)$ or that they are not physically active at all (38.7\%).

Health issue scores also do not differ among different ages, but the trend of greater scores can be noticed in case of women compared to men. Although without statistical significance, this trend is in accordance with the results of other researchers $(2,3,21,23)$, with female ultrasonographers more often reporting issues of this kind than their male colleagues. 
OSHA (Occupational Safty and Health Administration) guides for safe work state that information and education are also very important for the prevention of work related musculoskeletal disorders, along with the implementation of ergonomic positioning in the work of ultrasonographers $(1,27,28)$. It is said that it is necessary to motivate doctors to learn what is needed for easier and safer work in ultrasound diagnostics, so that it leads to the increase in their efficacy and effectiveness $(1,27)$. Our results, sadly, point to a very low level of awareness among the examined population. Over a half of the respondents, in all age groups, stated that they it was up to them to find information, which is in accordance with the results obtained in other studies, where ultrasonographers also mostly found information on these topics on their own (23). The same authors said that their respondents reported that their superiors in health care institutions did not pay attention to the implementation of the preventative measures and that they did not follow the advancements in the development of ergonomically better equipment. Almost half of our respondents think that no one in the institution where they work is responsible for giving information on these topics, or they do not know who is responsible. The level of awareness is especially low in the over 50 age group, which can be explained by greater use of the Internet in case of the younger groups and obtaining information in this way.

Research points to the fact that insufficient physical activity and too little attention paid to the work conditions are what most ultrasonographers in different studies have in common. The results of these studies are available in the literature $(33,34)$. Unfortunately, our results confirm the ones found in the literature.

\section{CONCLUSION}

Over $70 \%$ of the participants experience pain in the spine and joints which can be connected to ultrasound diagnostics work, regardless of age. These issues are slightly more frequent in women than in men. Health issues are in a positive correlation with the number of examinations per day and the number of working hours per day, as well as with the number of patients per week, but they do not correlate with the application of preventative measures during work.

The respondents implement the recommendations concerning safety at work and other preventative measures to a very small degree: they rarely have a break during work, they usually examine patients without stopping, they do not use conveniences during work enough and they are not physically active, regardless of age and gender.

Especially important conclusion is the nonexistence of good communication and very low implementation of preventative measures during work, which makes room for preventative-medical action among the population of ultrasonographers. Preventative-medical work should encompass becoming acquainted with the correct body positions during examinations, with the possibilities of the use of the conveniences which help to unburden the muscles and joints, as well as the height adjustment of the chair, desk and examination bed. It would be especially beneficial to organize interactive seminars, where information regarding the usefulness of preventative measures during work would be introduced through training and practical work. Printed materials, especially in the form of posters which would serve as reminders during work, would also have a purpose. However, the most important activity should be directed to motivating ultrasonographers to change their habits and accept recommendations.

\section{ETHICS APPROVAL AND CONSENT TO PARTICIPATE}

The study was conducted in accordance with the ethical standards of the committee responsible for human experimentation (institutional and national) and the Helsinki Declaration of 1975, as revised in 2013. Voluntary written and informed consent was obtained from each participant prior to enrollment in the study.

\section{CONFLICT OF INTERESTS}

The authors declare no conflicts of interest.

\section{FUNDING}

None.

\section{REFERENCES}

1. Baker JP, Coffin CT. The importance of an ergonomic workstation to practicing sonographers. J Unltrasound Med. 2013;32:1363-75

2. Necas M. Musculoskeletal symptomatology and repetitive strain injuries in diagnostic medical sonographers: a pilot study I Washington and Oregon. J Diagn Med Sonography. 1996;12:266-73.

3. Hill JJ, Slade MD, Russi MB. Anthropometric measurements, job strain, and prevalence of musculoskeletal symptoms in female medical sonographers. Work. 2009;33:181-9

4. Vanderpool HE, Fris EA, Smith BS, Harms KI. Prevalence of carpal tunel syndrome and other work-related musculoskeletal problems in cardiac sonographers. J Occup Med. 1993;35:604-10.

5. Magnavita, N., Bevilacqua, L., Mirk, P., Fileni, A.,\&Castellino, N. (1999). Work-related musculoskeletal complaints in sonologists. Journal of Occupational and Environmental Medicine. 41(11), 981-988.

6. Evans K, Roll S, Baker J. Work-Related Musculoskeletal Disorders (WRMSD) Among Registered Diagnostic Medical Sonographers and Vascular Technologists: A Representative Sample. Journal of Diagnostic Medical Sonography. 2009;25(6):287-299.

7. Oke KI, Adeyekun A. Patterns of workrelated musculoskeletal disorders among sonog-raphers in selected health facilities in Nigeria. J Appl Med Sci. 2013;2(4): 67-76. 
8. Mirk P, Magnavita N, Masini L, Bazzocchi M, Fileni A. Frequenza dei disturbi dell'apparato muscoloscheletrico negli ecografisti. Risultati di uno studio pilota Frequency of musculoskeletal symptoms in diagnostic medical sonographers. Results of a pilot survey. Radiol Med. 1999;98(4):236-41.

9. Pike I, Russo A, Berkowitz J, Baker JP, Lessoway VA. The Prevalence of Musculoskeleta Disorders Among Diagnostic Medical Sonograhers. Journal of Diagnostic Medical Sonography. 1997;13(5):219-227.

10. Irurhe NK, Okafor UC, Adekola OO, Odebiyi DO, Habeebu MYM, Sowunmi A. C. (2013).Work Related musculoskeletal discomforts (WRMD) in ultrasonologists: prevalence and risk factors. World J Med Sci. 2013;8:199-204.

11. Industry Standards for the Prevention of Work Related Musculoskeletal Disorders in Sonography. Journal of Diagnostic Medical Sonography. 2017;33(5):370-391.

12. Smith AC, Wolf JG, Xic G, Smith MD. Musculoskeletal pain in cardiac ultrasonographers: results of a random survey. J Am Soc Echocardiogr. 1997;10:357-625.

13. Vidaković A, Bulat P, Dželajlija S. Medicina rada II. Medicinski fakultet Univerziteta u Beogradu.

14. Gremark Simonsen, J. (2018). Ergonomic factors and musculoskeletal pain in sonographers. Lund: Lund University: Faculty of Medicine.

15. Arvidsson I, Gremark Simonsen J, Dahlqvist C, Axmon A, Karlson B, Björk J, Nordander C. Cross-sectional associations between occupational factors and musculoskeletal pain in women teachers, nurses and sonographers. BMC Musculoskelet Disord. 2016;17:35.

16. Kristensen TS, Hannerz H, Hogh A, Borg V. The Copenhagen Psychosocial Questionnaire--a tool for the assessment and improvement of the psychosocial work environment. Scand J Work Environ Health. 2005;31(6): 438-49.

17. Kuorinka I, Jonsson B, Kilbom Å, Vinterberg H, Biering-Sørensen F, Andersson $G$ et al. Standardised Nordic questionnaires for the analysis of musculoskeletal symptoms. Appl Ergon. 1987;18(3): 233-7.

18. Pike I, Russo A, Berkowitz J, Baker J, Lessoway V. The prevalence of musculoskeletal disorders among diagnostic medical sonographers. J Diagn Med Ultrasound 1997;13:219-27.

19. Muir M, Hrynkow P, Chase R, Boyce D, Mclean D. The nature cause, and extent of occulational musculoskeletal injuries among sonographers: recommendations for treatment and prevention. J Diagn Med Sonography. 2010;20:317-25

20. Rousseau T, Mottet N, Mace G, Franceschini C, Sagot P. Practice Guidelines for Prevention of Musculoskeletal Disorders in Obstetric Sonography. J Ultrasound Med. 2013;32:157-64

21. Evans K. Roll SC, Baker JP. Work-related musculoskeletal disorders (WRMSD) among registered diagnostic medical sonographers and vascular technologists. J Diagnost Med Sonography. 2009;25(6):287-99.
22. Marras WS. The Working Back - A systems View. John Wiley and Sons, Inc. Hoboken, New Jersey, 2008.

23. Evans K. Roll SC, Hutmire C, Baker JP. Factors that contribute to wrist-hand-finger discomfort in diagnostic medical sonographers and vascular technologists. J Diagnost Med Sonography. 2010;26(3):121-9.

24. Schoenfeld A. Transducer user syndrome: an occupational hazard of the ultrasonographer. Eur J Ultrasound. 1999;10:41-5

25. Dabholkar T, Shirodkar M, Shroff R. Ergonomic Risk Assessment of Sonographers during Abdominal and Pelvic Sonography. International Journal of Science and Research (IJSR). 2018;7(3):525-530

26. Attwood DA, Deeb JM, Danz-Reece ME. Ergonomic solutions for the process industries. Elsevier, Burlington USA 2004.

27. Murphey SL, Coffin CT. Ergonomics and sonographer well-being in practice. Sound Ergonomics. 2002;102: 1045-8.

28. NIOSH. Preventing work-related musculoskeletal disorders in sonography. Workplace Safety and Health. 2006; 1:148.

29. Bridger RS. Some fundamental aspects of posture related to ergonomics. Int J Industr Ergonom 1991;8:315.

30. Village J, Trask C. Ergonomic analysis of postural and muscular loads to diagnostic sonographers. Int J Industr Ergonom. 2007;37:781-9.

31. Gemark Simonsen J, Gard G. Swedish Sonographers' perceptions of ergonomic problems at work and their suggestions for improvement. BMC Musculoskelet Disord. 2016;17:391. 